\title{
LIKE IT OR NOT - SOCIAL MEDIA MARKETING IN B2B COMPANIES
}

Stefanie Paluch, TU Dortmund University, Germany Hartmut Holzmueller, TU Dortmund University, Germany

\begin{abstract}
Social-media marketing is growing rapidly. Social media tools such as blogs, wikis and networks like Facebook and Twitter are quite common in the business-to-consumer context. However the adoption of social media in business-to-business companies is still in an early stage due to privacy, security and content ownership concerns. The aim of our paper is to investigate the current use of social media tools in $\mathrm{B} 2 \mathrm{~B}$ companies and to analyze potentials and challenges of social media activities in the capital goods industry. We aim to develop managerial implications for B2B companies of how to implement social media activities and how to use social networks effectively for communication and customer retention.
\end{abstract}

References available upon request. 